\title{
SALVAGUARDA DEL MARCO CONSTITUCIONAL. LA AUTOPROTECCIÓN DEL ARTÍCULO 155 DE LA CONSTITUCIÓN ESPAÑOLA COMO HERRAMIENTA DE UNIDAD DE CRITERIO EN TIEMPOS CONVULSOS
}

\author{
SAFEGUARDING THE CONSTITUTIONAL FRAMEWORK. THE SELF-PROTECTION OF \\ ARTICLE 155 OF THE SPANISH CONSTITUTION AS A TOOL OF UNIT OF CRITERION IN \\ TIMES OF CONVULSION
}

\section{María Méndez Rocasolano}

Doctor en Derecho Universidad Complutense de Madrid . Full Bright by Harvard. Director del Departamento de Derecho Constitucional y Ambiental. Universidad San Antonio de Murcia UCAM. E-mail: mmrocasolano@gmail.com orcid.org/0000-0002-5345-8352

Convidada

RESUMO: La Constitución Española, en su propio cuerpo legal, establece mecanismos de protección ordinarios y otros de carácter extraordinario, siendo éste el caso del artículo 155. El análisis de su naturaleza, contenido y fundamentación, así como la legitimación que otorga al Gobierno para aplicarlo a través de las distintas fases de su procedimiento representa un ejemplo concreto de uno de los método de protección que la Constitución española consagra para hacer cumplir y respetar sus valores fundamentales. En Estados compuestos como los Estados Federados, la Federación de Estados o el Régimen Autonómico, en los que hay una división de competencias puede ser un elemento útil para la protección del marco constitucional y la definición de una unidad de actuación en tiempos convulsos.

Palavras-chave: Defensa de la Constitución. Estados de excepción. Excepcionalidad constitucional. Fuerza normativa de la Constitución. Orden Constitucional.

\begin{abstract}
The Spanish Constitution, in its own legal body, establishes ordinary protection mechanisms and others, of an extraordinary nature, this being the case of the article 155 . We analyze its nature, content and foundation, as well as the legitimacy that it grants to the Government to proceed with its application through the different phases of its procedure as a concrete example of a constitutional protection tool that the Spanish Constitution establishes to enforce and respect its fundamental values, which in compound States such as the Federated States, the Federation of States or the Autonomous Regime, in which there is a division of competences, it can be a useful element for the protection of the constitutional framework and the definition of a unit of action in troubled times.
\end{abstract}

Keywords: Defense of the Constitution. States of exception, constitutional exceptionality. Normative force of the Constitution. Constitutional Order. 
SUMÁRIO: Introducción. 1. Sentido extraordinario del art. 155 de la Constitución Española 2. Presupuestos materiales para el art. 155; Imputabilidad a una Comunidad Autónoma e incumplimiento o atentado grave contra el interés general de España. 3. Arquitectura procedimental. 4. Competencias de control. Conclusiones. Referencias.

\section{INTRODUÇÃO}

En este año 2020, que comenzaba estrenando la agenda de las Naciones Unidas para el Desarrollo Sostenible y que ha sido meta de múltiples proyectos y pretensiones en todos los órdenes, económicos, tecnológicos, sociales, culturales y jurídicos fijadas a comienzos del siglo XXl, la humanidad entera, todos los Estados del Planeta sin excepción, han sido azotados por la pandemia del Covid 19 con insólita crueldad. La realidad en muchos países ha puesto en evidencia la capacidad de respuesta del marco jurídico político para resolver el impacto del virus, aumentando más todavía el descrédito que la sociedad civil tiene de la política y sus representantes, que juzga corruptos e ineficaces en términos generales. La sociedad líquida, el hedonismo individualista y el consecuente desprecio de las leyes, presiona temerariamente los cimientos del pacto social conquistados desde la razón y los valores del humanismo en la cultura euroatlántica. En este panorama debemos recordar que frente a la fuerza del Poder y los poderes, la construcción dogmática de las Constituciones como normas superiores del ordenamiento jurídico, permiten la supremacía de la dignidad de la persona y los derechos que le son inherentes en esquemas de orden democrático. El concepto de Constitución lleva implícito un carácter de seguridad, de amparo por la norma que gestiona el vivir y el devenir del individuo y sus grupos, de la sociedad y las instituciones con los dictados de la Democracia, la coherencia axiológica y la Justicia, lo que en estos tiempos convulsos resulta fundamental para gestionar los estados de excepción con tales criterios, protegiendo en definitiva los derechos fundamentales, la paz social y el bien común de las sombras que se mantienen al acecho con versiones utilitaristas de la sociedad, del ser humano, y la del aparato normativo e institucional que regula su comportamiento. El constitucionalismo decimonónico ya se preocupó de estos riesgos, creando mecanismos de protección de entre los que destaca la autodefensa del texto constitucional que en el caso español se realiza a través del artículo $155^{1}$. A continuación como resultado de la investigación que pertence a la línea Arquitectura axiológica del Derecho Constitucional y dinamogénesis de los valores en la sociedad del siglo XXI de la UCAM se ha reflexionado sobre su contenido poniendo como ejemplo la activación que se realizó en España para corregir la anomalía de política territorial que pretendía la independencia de Cataluña. Sirva como ejemplo para revisar las consecuencias, necesidades y desarrollo de esta figura cuando se levantan voces, en cada Estado las suyas, que quieren cambiar la embarcación que nos mantiene a flote en medio de la tormenta. En este sentido la aplicación del mencionado artículo 155 es el mecanismo que dirige a puerto seguro la nave constitucional; es en dique seco cuando procede en situación de normalidad, cualquier revisión, mejora y pretensión democrática de su naturaleza y contenido, cuyo desarrollo escribe la historia de los pueblos y las naciones.

La autodefensa de la Constitución es una institución propia del constitucionalismo euroatlántico, dónde los órdenes constitucionales con expresiones propias, han incorporado mecanismos de protección de sus normas supremas. En España se cristaliza en la intención de

\footnotetext{
${ }^{1}$ El artículo 155 de la Constitución establece lo siguiente: "1. Si una Comunidad Autónoma no cumpliere las obligaciones que la Constitución u otras leyes le impongan, o actuare de forma que atente gravemente al interés general de España, el Gobierno, previo requerimiento al Presidente de la Comunidad Autónoma y, en el caso de no ser atendido, con la aprobación por mayoría absoluta del Senado, podrá adoptar las medidas necesarias para obligar a aquélla al cumplimiento forzoso de dichas obligaciones o para la protección del mencionado interés general. 2. Para la ejecución de las medidas previstas en el apartado anterior, el Gobierno podrá dar instrucciones a todas las autoridades de las Comunidades Autónomas."
} 
cumplir con el dictado preámbular de conseguir una sociedad democrática avanzada e imponer un orden social pacifico y justo.

\section{SENTIDO EXTRAORDINARIO DEL ART. 155 DE LA CONSTITUCIÓN ESPAÑOLA}

Las medidas de protección ordinaria del orden constitucional en la tensión Estado y Comunidades Autónomas, (en adelante CCAA) están reguladas en el art.153 de la Carta magna española ${ }^{2}$. En él se describen las principales vías de control ordinario del Estado, siendo el texto del art.155 el que se ocupa de los casos de carácter extraordinario, como bien expresa el Tribunal Constitucional en sus sentencias del 22 de febrero de 1982 y 22 de marzo de $1988^{3}$.

La doctrina española considera esta institución como una forma de control excepcional para casos, normalmente inusuales (MOLINA DEL POZO, 2015). Algunos, han hablado de cláusula de plenos poderes o de ultima ratio, especialmente dentro del diálogo social y político, lo que se aleja de su sentido real, que es jurídico constitucional y se basa en revertir una situación, fuera del marco constitucional y con graves implicaciones respecto a la fórmula política y jurídica del Estado a la normalidad, como ocurre en los casos de excepción alarma y sitio. No es pues una manifestación de derecho singular (ius singulare), sino una institución normalizada que representa una forma de control extraordinaria, en este sentido se ha de justificar su aplicación "en su cualidad de instrumento normal y ordinario de la supervisión estatal, también normal y ordinaria, como es lo propio de toda actividad administrativa y ejecutiva" (GARCÍA DE ENTERRÍA, 1983 p.103).

Interesa el examen de esta figura en la actualidad cuando como consecuencia de la distribución de competencias en los Estados compuestos, los responsables del Estado central y los autonómicos buscan protagonismo político en la resolución y propuestas para la gestión de la pandemia que estamos viviendo. Resulta una exigencia moral y ética la colaboración interterritorial e institucional más allá de las diferencias ideológicas y partidistas ante el reto de superar con las menos muertes posibles la crisis sanitaria, económica y social a la que se enfrentan los Estados. Vivimos sin embargo como los aparatos de los partidos políticos ven una oportunidad en la penosa situación que está padeciendo la humanidad y con la intención de sacar rédito electoral tratan de buscar el reconocimiento y protagonismo en las medidas que proponen. Este es el caso de la compleja relación en la que se encuentran comunidades autónomas de diferente signo que el gobierno del Estado en España y en el mundo, pues esta vergonzosa realidad se da en todas las arenas nacionales donde vemos enfrentados a los líderes y gobernantes cuando es preciso tener una unidad de criterio en la gestión de la realidad que estamos viviendo. Este principio de unidad es el fundamento esencial del Estado autonómico (PUNSET BLANCO, 1987 ) apuntado desde las primeras sentencias del Tribunal constitucional que ponían de manifiesto que el Estado se constituye no sólo en un límite de la autonomía, sino además en el origen y fundamento de la misma. Así la unidad del Estado, se concreta en la posibilidad de que los poderes centrales supervisen y controlen la actividad de las colectividades-miembros. La concepción unitaria del Estado impone incorporar mecanismos apropiados para que la organización que detenta la personalidad jurídica superior y originaria se reserve la fiscalización de la actividad desarrollada por los otros entes territoriales (SOSA WAGNER, 1979). En este sentido revisaremos cómo el mencionado a artículo 155, representa una vía para ordenar tal relación sin que la aplicación del precepto se convierta en una forma indirecta para lograr una situación de dependencia jerárquica permanente $\mathrm{u}$ ocasional, ni que el Gobierno de un país quede subordinado a la voluntad independiente de sus entidades territoriales.

\footnotetext{
${ }^{2}$ Debemos recalcar, que en la mayoría de Constituciones, estas medidas de control tienen otras fórmulas mucho más coercitivas y agresivas que la elegida en España. En algunas constituciones europeas como en la italiana, el mismo precepto autoriza la adopción de medidas tales como la disolución de los órganos autonómicos o suspensión del ejercicio de competencias.

${ }^{3}$ S.T.C. 6/1982, de 22 de febrero y SS.T.C. 27/1987, y, 49/1988.
}

Revista de Direito Brasileira | Florianópolis, SC | v. 26 | n. 10 | p. 195-206 | Mai./Ago. 2020 
En esta cuestión la política tiene un notable protagonismo pues el art.155 no autoriza cualquier clase de medidas ni tiene por destinatarios a los ciudadanos de las Comunidades, sino a sus representantes políticos, a los encargados de la administración y gestión de lo público (CODES, $2018)^{4}$.

\section{PRESUPUESTOS MATERIALES PARA EL ART.155; IMPUTABILIDAD A UNA COMUNIDAD AUTÓNOMA E INCUMPLIMIENTO O ATENTADO GRAVE CONTRA EL INTERÉS GENERAL DE ESPAÑA}

Los requisitos o presupuestos materiales indispensables para que se pueda aplicar el art.155, junto con las decisiones que se deben tomar y quiénes las deben efectuar dependen de que los actos del gobierno de una Comunidad Autónoma atenten contra el interés general del país ${ }^{5}$, la actuación debe ser imputable a una Comunidad Autónoma, entendida como colectividad donde sus poderes Públicos son los responsables, a saber: Asamblea Legislativa y el Consejo de gobierno, encabezado por el Presidente autonómico (BASSOLS COMA, 1988 ).

Existen un par de artículos que hacen discernir sobre los actos de la Asamblea legislativa, y es el art. 161.2 de la CE, y el art. 76 de la Ley Orgánica del Tribunal Constitucional (en adelante TC) en España, ya que las resoluciones adoptadas por este órgano no pueden ser más que acuerdos o leyes sin fuerza de ley, y esto significa, que el Gobierno, sin necesidad de acudir al Senado puede suspender cualquier disposición o resolución, acudiendo a la vía, de la inconstitucionalidad ante el Tribunal Constitucional ${ }^{6}$.

Por tanto, objeto de este procedimiento de control, son los actos imputables al Poder Ejecutivo de una CCAA, que por acción u omisión, incumplan gravemente una obligación constitucional, y que pese haber sido impugnados, sigan adelante con sus pretensiones. El otro requisito indispensable es que, para la aplicación del procedimiento, la comunidad autónoma, como órgano subordinado del Estado, ha de haber incumplido un deber importante o haber tenido una actitud pasiva ante algún deber constitucional autonómico. Procediéndose al respaldo constitucional cuando se violenta el interés general de España y naturalmente del pueblo español. La Constitución, no sólo se pronuncia sobre las obligaciones no cumplidas o el grave atentado al interés general de España, sino que también establece cuáles concretamente pueden dar lugar a la aplicación de las medidas de corrección.

En primer lugar, se describe el incumplimiento de manera general ${ }^{7}$. La generalidad del incumplimiento ha de entenderse en el sentido que marca el principio de legalidad y de jerarquía normativa de la Constitución, estando alejado el artículo 155 de un control fuera de lugar del Estado sobre la política y gestión de las autonomías. La actuación estatal requiere que el incumplimiento sea real y grave no siendo suficiente el error (LEGUINA VILLA 1981) ${ }^{8}$ En este sentido se ha manifestado la jurisprudencia del Tribunal Constitucional expresando el carácter extraordinario y excepcional del artículo que ha de alejarse de aplicaciones que creen la incoherencia de, aplicando

\footnotetext{
${ }^{4}$ Interesa aquí destacar que el art.155 no tiene un desarrollo legislativo y si bien se ha intentado desarrollar no se ha conseguido justamente por la implicación política mencionada.

${ }^{5}$ Así pues no cabe la posibilidad de que las CCAA sean las que piden responsabilidad a otras Entidades Locales y, mucho menos al Estado. Este precepto sólo hace referencia como sujeto actor de dichos actos a las CCAA como ente político o territorial y a sus miembros políticos.

${ }^{6}$ En el período 2007-2016 el Tribunal Constitucional ha dictado 87 sentencias en procedimientos de control incidental de leyes autonómicas por vía de cuestión de inconstitucionalidad, pueden consultarse en el Boletín oficial del Estado español, www.boe.es.

${ }^{7}$ Se ha definido doctrinalmente al concepto de incumplimiento, en términos de acción u omisión, el cumplimiento defectuoso o fuera de rango de tiempo o extemporáneo, además de declaraciones expresas de un propósito descarado. ${ }^{8}$ Cabe en este extremo poner de relieve la exigencia de responsabilidad, también por los errores del colectivo político, sumergirnos en este discurso nos alejaría de nuestra discusión.
}

Revista de Direito Brasileira | Florianópolis, SC | v. 26 | n. 10 | p. 195-206 | Mai./Ago. 2020 
la Constitución generar una realidad inconstitucional y antidemocrática que atente contra la lealtad española (CALAFELL FERRA, 2000)

En segundo lugar, se deben excluir ciertas obligaciones que no vienen determinadas por la Constitución u otras leyes orgánicas. El TC deja claro en varias sentencias9, que no todo lo denominado "leyes", puede formar parte de esas obligaciones a cumplir, es decir, el incumplimiento de los Reglamentos u otras normas de rango inferior a la ley, quedan excluidas de estas obligaciones para con el Estado, ya que se interpreta que el carácter excepcional del precepto guarda una relación importante con el carácter restrictivo de las leyes. También debemos acordarnos en esta parte de los Tratados firmados con la UE, pues los Estados miembros deben cumplir con sus deberes ${ }^{10}$, aun teniendo libertad para organizar como lo estimen (GÓMEZ ORFANEL, 2003). Con ello el art. $155 \mathrm{CE}$, sujeta las actuaciones autonómicas al ordenamiento jurídico del Estado, y al orden normativo e institucional de la Unión Europea.

El interés general al que se refiere el artículo, integra a todas las CCAA que forman el conjunto del país, es decir, no se puede hablar de un interés general conforme a una ideología, una forma de entender la política o la gestión de lo público. El contenido de tal interés general se corresponde con el de los principios que orientan el orden constitucional, que en el caso español, entendemos que vienen expresados en el preámbulo que determina el sentimiento constitucional (LUCAS VERDU, 1985) y la dimensión axiológica de su articulado (MENDEZ ROCASOLANO, 2011). La articulación de los deseos preambulares de "establecer la justicia, la libertad y la seguridad y promover el bien de cuantos la integran" y los valores superiores del ordenamiento jurídico determinan el contenido del denominado interés general, indisolublemente trabado en una unidad de contenido e interpretación con el bien común, la seguridad y la paz social junto con la prevalencia de la dignidad de la persona y los derechos que le son inherentes en libertad e igualdad. Lejos de conformar una realidad estática este interés se expande, crece y germina en nuevos derechos y obligaciones que surgen a través de la dinamogénesis de los derechos (MENDEZ ROCASOLANO, 2000 ) donde según avanza el inexorable progreso que descubre valores nuevos, la comunidad, sintiéndose reconocida con ellos, acepta que sean inspiración de su convivir y en su devenir... se hacen carne alumbrando un plexo normativo e institucional que impone la concreción de nuevos derechos ${ }^{11}$, como el Derecho a un Estado Derecho (BONAVIDES, 2014) que dirija la acción del Estado y sus instituciones bajo el cumplimiento real del compromiso adquirido con la ciudadanía de acciones eficaces y eficientes en tiempos de crisis a través del mandato directo y finalista que se impone a los poderes públicos de gestionar lo público para la seguridad y desarrollo de la población ${ }^{12}$.

\section{ARQUITECTURA PROCEDIMENTAL}

El procedimiento de aplicación del art.155 de la CE consta de cuatro fases, importantes todas, cuyos trámites quedan claramente reflejados en el Reglamento del Senado. En su desarrollo

${ }_{9}$ SS. 18/1982, de 4 de mayo; 35/1982, de 14 de junio y 39/1982, de 30 de junio.

${ }^{10}$ En concreto respecto a las normas de la Unión Europea ya se produjo una vez con el previo requerimiento al Presidente de las Islas Canarias con el tema del impuesto del tabaco SÁNCHEZ RODRIGUEZ, L. El articulo 93 y el bloque de la constitucionalidad. Págs. 242 a 245. Ed. Civitas, Madrid, 1981.

${ }^{11}$ La teoría de la dinamogénesis de los valores y el Derecho desde el año 2000 vine utilizándose en múltiples ocasiones para justificar la existencia de derechos fuera del apoyo constitucional. Para su conocimiento y comprensión me remito a la explicación del proceso recogida en MENDEZ ROCASOLANO, M.(2013) "Retos constitucionales sobre derechos humanos: los derechos de los niños desde perspectivas axiológico normativas", en Revista Thesis Juris - São Paulo, v.2, n.1. Páginas 328 a 340 .

${ }^{12}$ Interesa destacar la obra del brasileño BONAVIDES P. (2014) Del Estado Liberal al Estado Social, donde explica magistralmente el contenido de este derecho. Para ampliar en cuanto a la dinamogénesis de los derechos nos remitimos al "Estudio preliminar de la traductora: la teoria de la dinamogenesis de los valores y el derecho a un estado social. Páginas 21 a 35

Revista de Direito Brasileira | Florianópolis, SC | v. 26 | n. 10 | p. 195-206 | Mai./Ago. 2020 
el Gobierno tiene una serie de obligaciones que junto con el ejercicio de sus funciones, ha de organizar eficazmente el devenir de la población, titular al fin y al cabo de la soberanía del Estado, como estamos manteniendo por encima de las medidas de política territorial o ideológica de las entidades autonómicas.

\section{Fase 1: Inspección y Compulsión Estatal}

Es en esta primera fase, el Gobierno revisa la existencia de algunos de los presupuestos materiales anteriormente citados, es decir, aquí, se ha de observar si la comunidad autónoma ha incumplido de forma importante alguna obligación legal o constitucional, o si ha atentado gravemente contra el interés general del país, además de hacer un profundo análisis del posible conflicto antes de tomar medidas al respecto. En definitiva, la Constitución en España atribuye al Gobierno la facultad de juzgar si alguna comunidad está incumpliendo o atentando en su caso, contra el país, siendo el Gobierno el responsable del controlar tal actividad (BACIGALUPO SAGESSE, 2018) ${ }^{13 .}$

Existen diferentes cauces por los cuáles el Gobierno puede tener constancia de que se están infringiendo preceptos legales o constitucionales. El Consejo de Ministros puede tener conocimiento de la problemática a través de la inspección, y la compulsión estatal o por vías públicas tales como una nota de prensa en un periódico, una queja directa al Gobierno por parte de un funcionario residente en la comunidad o, simplemente por aquellos ciudadanos que demandan la protección y garantía que representa el interés general, la paz y el bien común, alterado o comprometido por la actividad autonómica ${ }^{14}$.

Ante el conocimiento de incumplimiento o atentado contra España y los españoles, el Gobierno puede activar el mecanismo del artículo 155. Aquí, cabe recordar que este método constitucional, como hemos mencionado líneas arriba, se ejercita cuando no puedan usarse otras vías o bien, cuando ya se hayan usado todos los recursos ordinarios prudentes y no se pueda resolver el conflicto de otra manera. En definitiva, el carácter coercitivo en ocasiones, y restrictivo del precepto sólo podrá usarse en situaciones críticas.

\section{Fase 2: Requerimiento de Advertencia}

Una vez, que el Gobierno decide aplicar el art.155 se procede a realizar una última advertencia a la comunidad autónoma. Así el Consejo de Ministros, realiza un requerimiento al Presidente autonómico con la intención de que rectifique y se ajuste su comportamiento al dictado constitucional. El requerimiento, ha de estar cuidadosamente fundado y motivado legal y constitucionalmente $^{15}$, pues la motivación del hecho actor del precepto debe estar escrita para que no quepa ninguna duda al respecto de la oportunidad en la aplicación de este artículo (GARCÍA DE ENTERRÍA, 1983)

El Presidente de la comunidad tiene el deber de contestar, ya que el requerimiento es un acto recepticio, (GARCÍA TORRES, 1984) pero ni la Constitución, ni el Reglamento del Senado indican un plazo. No queda sin embargo ad calendas graecas, ya que tal demora insta a que el

\footnotetext{
${ }^{13}$ Todo esto tiene una gran notabilidad a los efectos de lo que más tarde se indicará en cuanto a la actuación de la Mesa del Senado desde el punto de vista procedimental

14 Como veremos más adelanteel Gobierno, puede adoptar las medidas que crea necesarias para la solución del problema por si solo, siempre y cuando el requerimiento sea atendido. La CCAA, le da permiso al Consejo de Ministros, mediante sus argumentos y demás pretensiones en la contestación al requerimiento, de adoptar medidas que considere necesarias. La comunidad requerida debe realizar también una clara exposición de motivos en su contestación para que, en el caso de que el Gobierno, deba argumentar las medidas adoptadas en el lugar de la comunidad, pueda éste tener por escrito todas ellas para mostrárselas al Senado y a los posibles órganos, y no quepa duda de la procedencia de la adopción.

${ }^{15}$ GARCÍA DE ENTERRÍA, E.,(1983). La ejecución autonómica de la legislación del Estado. Págs 171-176.
}

Revista de Direito Brasileira | Florianópolis, SC | v. 26 | n. 10 | p. 195-206 | Mai./Ago. 2020 
Gobierno considere por no respondido el requerimiento ${ }^{16}$. Debido a su carácter político jurídico podrían existir multitud de problemas diferentes con escenarios y plazos distintos, lo que hace comprensible la no fijación de un término debido al carácter extraordinario del precepto, y a la dificultad de acuerdo entre las dos partes.

En cuanto al requerimiento, debe ser claro y conciso en lo que se describe, es decir, debe precisar el incumplimiento o la omisión de los deberes constitucionales por los que responde. También puede contener las propuestas para corregirlos. Así se cumple con los principios básicos de resolución de conflictos que indican que cuánto más claro sea el requerimiento y más explícitas sean sus palabras, más rápido y sencillo se podrá resolver ${ }^{17}$. A continuación el Senado, debe aprobar la decisión del Gobierno .

\section{Fase 3: Formas de Atender el Requerimiento}

Se dan tres modalidades a la hora de atender al requerimiento emitido por el Presidente del Gobierno.

Si el Presidente de la Comunidad Autónoma atendiera al requerimiento, podría hacerlo de dos formas. O bien, anunciando la adopción de las medidas necesarias para cumplir con las obligaciones a las que hace referencia el requerimiento por parte de los órganos competentes de la comunidad en cuestión, o mostrándose conforme con las medidas de adopción presentadas por el Gobierno y anunciando su asunción (CRUZ VILLALÓN 1988). En éste caso el procedimiento pasaría directamente a la fase de ejecución sin necesidad de intervención de la cámara de representación territorial (en España el Senado).

En caso de que la CCAA corrija y adopte las medidas necesarias en cumplimiento de sus obligaciones legales, el Gobierno puede optar por estar de acuerdo y satisfecho con las medidas propuestas en la contestación al requerimiento, o entender que bien son insuficientes o que no están del todo enfocadas a solucionar el problema. En ambos casos, el Gobierno podrá acudir al Senado para que le remita autorización para actuar, en concreto el silencio al que antes hacíamos referencia también le legitima para solicitar la aprobación de la Cámara Alta.

Una vez pasado este trámite, el Gobierno debe realizar un segundo acuerdo, en el cual indicará las medidas a adoptar, es decir, si ha existido conformidad con las medidas propuestas por la comunidad autónoma, si ha decidido adoptar las medidas propuestas por el Gobierno y cómo las pondrás en práctica, cabe también continuar con el procedimiento y acudir al Senado. El Gobierno puede solicitar aclaraciones o indicaciones en cualquier momento, pues o debido al carácter extraordinario de la situación, todas las medidas y trámites dirigidos a la solución y mejora del conflicto, sirven. Destacamos aquí que el Gobierno es libre en cualquier momento de paralizar el procedimiento, aunque haya pedido autorización al Senado para aclarar y solucionar el conflicto, abriéndose la vía de la mediación y el diálogo.

\section{Fase 4: Contenido de las medidas propuestas por el Gobierno}

Llegados a este punto, en el que el Gobierno decide presentar escrito al Senado para solicitar aprobación para actuar, aquél, debe presentar una propuesta por escrito ante la Cámara en la cual debe estar contenido las medidas propuestas en el requerimiento y la explicación

\footnotetext{
${ }^{16}$ GARCÍA TORRES. El artículo 155 de la Constitución española y el principio constitucional de autonomía. Madrid, 1984. Ed. Instituto de Estudios Fiscales. Pág.1271.

${ }^{17}$ A pesar de mis reticencias para el uso de la mediación fuera del ámbito comercial, interesa revisar la posibilidad de la mediación dentro de la política, que sirve como actuación concreta para reducir la posible tensión entre el Gobierno y los órganos autonómicos, normalmente de partidos políticos enfrentados. Para una comprensión de mi posición recomiendo la lectura de Entre la libertad, la justicia y la eficacia I. Marco europeo de la mediación y la afección de los derechos fundamentales (el derecho a la tutela judicial efectiva) de acceso en . academia\&oq=academia+\&aqs=chrome..69i57j69i6012.4093j0j7\&sourceid=chrome \&ie=UTF-8
}

Revista de Direito Brasileira | Florianópolis, SC | v. 26 | n. 10 | p. 195-206 | Mai./Ago. 2020 
desarrollada y detallada de porqué se procedió de esta manera ante el Presidente de la comunidad, así como los incumplimientos que han generado tal situación (MUÑOZ MACHADO,1982). El Senado sólo puede responder o aceptar las medidas propuestas por el Gobierno que hayan sido plasmadas en el requerimiento anterior al Presidente de la autonomía. En este escrito, se pueden proponer todas un total de las medidas solicitadas, en el caso de que todas hayan sido rechazadas o no contestadas por la comunidad autónoma, o también sólo aquellas no que se atendido.

Las medidas presentadas no deberán ser propuestas por el Gobierno ni aprobadas por el Senado sin que reinen los principios de gradualidad y proporcionalidad con el problema surgido. Es decir, cuando se presenta un conflicto de semejante magnitud como podría ocurrir, sin un exquisito uso del Derecho Constitucional y de la ingeniería jurídico podrían derivarse problemas más graves que se refieren principalmente al abuso del Derecho y al autoritarismo.

En este sentido resultan pertinentes, medidas como la rescisión o suspensión de los convenios o acuerdos adoptados por la CCAA y el Estado, o también suspensión de acuerdos o resoluciones de órganos autonómicos. En cuanto a la adopción de medidas económica o de bloqueo, con ellas se eleva la presión ${ }^{18}$ que alcanza niveles elevados con medidas que se alejan del carácter pacífico y dialogante, representando una vis compulsiva del Poder ejecutivo sobre el autonómico. Entre ellas se encuentran la disolución de los órganos de la comunidad y sustitución de sus titulares, medida que si bien puede ser eficaz, tiene un importante desgaste político y social pues si ciertamente no se trata de sancionar a la comunidad ni a sus órganos, sino de hacer que cumplan sus obligaciones, la realidad es que se apartan de sus funciones a los titulares de los mismos. En el mismo sentido se encuentra la sustitución de la actuación de la Administración autonómica e igualmente el uso de las Fuerzas y Cuerpos de Seguridad del Estado. En cualquier caso, pueden ser adoptadas y validadas por el Senado cuando fuera necesario para el restablecimiento de la normalidad constitucional.

\section{Fase 5: Comisión y Pleno del Senado}

El escrito que el Gobierno realiza con todas las circunstancias ocurridas y las medidas propuestas, se presenta ante la Comisión de Autonomías y de Organización y Administración Territorial. Este órgano debe requerir según dispone el art. 189.3 del Reglamento del Senado, "al Presidente de la Comunidad Autónoma para que en el plazo que se fije remita cuantos antecedentes, datos y alegaciones considere pertinentes y para que designe, si lo estimara procedente, la persona que asuma la representación a estos efectos". A continuación se dará audiencia a la comunidad autónoma afectada para que dé su versión y punto de vista sobre la situación. Éste trámite se desarrolla con cierta celeridad ${ }^{19}$. Ahora bien, la Comisión, a la vista de las alegaciones y datos de la CCAA propone al Pleno la autorización o no del precepto constitucional expresado en el artículo 155. En caso de que se produzca la autorización, el Pleno ha de expresar en su escrito la lógica de las medidas propuestas y los razonamientos pertinentes, tanto jurídicos-políticos como normativos, por los cuales se debe aprobar esta determinación. Además este órgano podrá condicionar y modificar alguna de las proposiciones para detallar y aclarar, alguna medida allí presentada. En este sentido el Pleno del Senado en su art. 189.5 establece que, previo debate con dos turnos a favor, dos en contra y turno de portavoces, aprobará o rechazará la propuesta, y ésta ha de aprobarse por mayoría absoluta, ya que de no ser alcanzada, la propuesta se entenderá rechazada.

\footnotetext{
18 Y, además una de las medidas más prácticas y conveniente sería que el Gobierno asumiera el cargo de dictar instrucciones directamente a la comunidad, que éste se subrogara en ciertas tareas para su incumplimiento, en actos de la CCAA.

${ }^{19}$ Las CCAA tienen un representante en el Senado y no se produce un desplazamiento y además, el requerimiento realizado por el Gobierno, pone sobre aviso a la comunidad para que ésta haya tenido tiempo para reunir tantos papeles, datos y demás circunstancias que pudieran dar lugar a ser escritas y presentadas.
}

Revista de Direito Brasileira | Florianópolis, SC | v. 26 | n. 10 | p. 195-206 | Mai./Ago. 2020 
El Reglamento del Senado no se pronuncia sobre si el Gobierno puede o no retirar su propuesta de aplicación del precepto, pero como ya sabemos al ser de carácter extraordinario esta situación, se entiende que pueda retirarse, bien por acuerdo o por el cumplimiento.

\section{Fase 6: Puesta en Práctica por el Gobierno}

En la última fase de este procedimiento el Gobierno pone en práctica las medidas aprobadas por el Senado ${ }^{20}$ no tiene obligación de llevar a cabo todas las medidas propuestas, ni de incluso aplicarlas si desapareciese la situación que las ha generado ${ }^{21}$. La autorización del Senado, es una habilitación puntual y provisional para un caso concreto (ZARATE CONDE, 2014), razón por la que las medidas propuestas y sus circunstancias, así como datos y demás, llevan fecha y distinciones para no poder ser utilizadas nuevamente. Una vez restaurado el orden en político constitucional, estas medidas y la presión e intervención del Gobierno, desaparecen.

\section{COMPETENCIAS DEL CONTROL}

Las decisiones del Senado y la ejecución de éstas por parte del Gobierno tendrán un control constitucional, no en vano la soberanía reside en el pueblo del que emanan los poderes del Estado en España. Así pues, el Senado a pesar de ser la Cámara de representación territorial en España, únicamente puede autorizar o no las medidas presentadas por el Gobierno para obligar a la comunidad autónoma a cumplir con las obligaciones afectadas, no pudiendo aportar nuevas propuestas. En el caso de que de autorizase por el Pleno y no fuera procedente el Senado incumpliría la legalidad por vicio de incompetencia. ${ }^{22}$.

Si el Gobierno realizase los actos recibidos por autorización de la Alta Cámara podrían ser éstos objeto de recurso de amparo ante el TC, siempre y cuando se den las infracciones del ordenamiento jurídico que den lugar a la utilización de dichos procedimientos. Pueden dar lugar también, a la revisión de la decisión del Gobierno de la utilización del art. 155 de la CE o del acuerdo del Senado autorizando este uso. Por tanto, no están exentas del control constitucional estas medidas y propuestas.

Igualmente el Congreso de los Diputados, puede utilizar los medios de control políticos de los que dispone en relación con las actuaciones del Gobierno, ya que no existe precepto alguno que excluya dicha actuación. Esta situación no es de impedimento aunque la resolución del Senado pueda ser revocada o modificada. En algunas ocasiones se ha planteado el control del Parlamento (TOLIVAR ALAS, 1981) justificado ser de mayor garantía el legislativo al completo, sin embargo la participación del Congreso de los diputados no asegura mayor rendimiento ni mejoras procedimentales, al contrario podría presentar numerosos inconvenientes basados en mayores discrepancias y el aumento del tiempo dedicado al procedimiento.

\section{CONCLUSIONES}

De forma concreta el articulo 155 representa un mecanismo de salvaguarda y garantía del marco constitucional español que al estar constitucionalizado se configura como un procedimiento de autoprotección en lo que se refiere al cumplimiento autonómico con el imperio de ley y de los

\footnotetext{
${ }^{20} \mathrm{El}$ Gobierno, no puede llevar a cabo las medidas propuestas en su requerimiento previo, hasta que el Senado no autorice de forma escrita su aprobación, si lo hiciera, la CCAA no tendría porque acatar ni cumplir las medidas exigidas, ya que estaríamos ante una situación de inconstitucionalidad y se sería nula de pleno derecho esta decisión

${ }^{21}$ La aprobación del Senado puede ser modificada o revocada ya que si cesa la situación que dio lugar a este procedimiento, no tiene más sentido.

${ }_{22}$ Este conflicto de competencia viene reflejado en una sentencia del TC que explica y desarrolla jurídicamente lo anteriormente citado S.T.C. 11/1984, de 2 de febrero, fundamento jurídico 2.
}

Revista de Direito Brasileira | Florianópolis, SC | v. 26 | n. 10 | p. 195-206 | Mai./Ago. 2020 
mandatos constitucionales con el interés general de España como referente. El Gobierno, requiere al Presidente de la Comunidad Autónoma que se ha apartado de la senda constitucional para que adopte las medidas necesarias, obligándolo en su caso al cumplimiento forzoso de la misma. En caso de no atender al requerimiento, el Gobierno podrá solicitar la aprobación de estas medidas al Senado. En la actual pandemia, las entidades territoriales de signo político contrario al Gobierno del Estado no están cumpliendo de forma coherente sus obligaciones esta vía se configura como una posible solución a esta incoherencia., sin acudir al coste social , económico, institucional y humano de los Estados de excepción.

Ciertamente la aplicación de este precepto se ha considerado por políticos y tribunales como excepcional o extraordinario, por no ser de utilidad habitual en el control Estado-CCAA. Sin embargo, los presupuestos materiales que se deben dar para la aplicación de este, así como el procedimiento llevado a cabo por el Gobierno y el Senado, expresan un método más ordinario que extraordinario.

Las comunidades autónomas que forman España tienen que cumplir con las obligaciones que la Constitución y las leyes les señalan y, esto, queda expuesto en la redacción del art.155, que ampara al Gobierno a actuar cuando además de atentarse o violentar el interés general del país, se pone en situación de riesgo nacional a sus ciudadanos e instituciones.

Requerir al Presidente destaca el carácter pacífico y parlamentario del precepto, que trata de solucionar un posible conflicto de jerarquía. La cámara del Senado, tiene un poder fundamental de aprobación y aplicación del artículo, y su actuación refleja de nuevo la prevalencia de la Democracia que se quiere plantear en la resolución del conflicto.

En definitiva, la propuesta del Gobierno de aplicación del art. 155 no es más que un método de actuación ordinaria ante una situación extraordinaria como el peligro de contagio del Covid representa junto con las medidas sanitarias y sociales vinculadas. Es decir, un método de protección que la Constitución consagra para hacer cumplir y respetar sus valores fundamentales, lo que en Estados compuestos como los Estados Federados, la Federación de Estados o el Régimen Autonómico de España en los que hay una división de competencias puede ser un elemento útil para la unidad de actuación en tiempos convulsos .

\section{REFERENCIAS}

ALZAGA VILLAAMIL, O \& GÜTIERREZ GÜTIERREZ, I.(1998). Derecho Político español según la Constitución de 1978. Ed. Ramón Areces. 1998. Madrid. Págs. 676-679.

BACIGALUPO SAGESSE, M. (2003). Sinopsis artículo 155 constitución Española. Congreso de los Diputados. Madrid.

BASSOLS COMA, M. (1988). Constitución Española de 1978: Artículos 143-158. Ed, Derecho Reunidas. Madrid. Pág. 457.

BONAVIDES P. (2014). Del Estado Liberal al Estado Social. Trad. María Méndez Rocasolano Ed. Astrea, Argentina.

CALAFELL FERRA, V.J.(2000). “ La compulsión o coerción estatal: estudio del artículo 155 de la Constitución Española” en Revista de Derecho Político, núm. 48-49. Madrid.

CODES J.M. (2018). Sinopsis artículo 155 constitución Española. Congreso de los diputados. Madrid. 
CRUZ VILLALÓN, P. (1988). La protección extraordinaria del Estado. Ed. Civitas. Madrid. Págs 693.

GARCÍA DE ENTERRÍA, E.(1983). La ejecución autonómica de la legislación del Estado. Ed. Civitas. Madrid Págs 171-176.

GARCÍA TORRES,I (1984). El artículo 155 de la Constitución española y el principio constitucional de autonomía. Ed. Instituto de Estudios Fiscales Madrid. Pág.1271.

GÓMEZ ORFANEL, G.(2003). ¿Una Constitución permanente e inalterable? La necesidad y beneficios de las reformas constitucionales. Pág. 56-57.Logroño

LEGUINA VILLA, J. (1981). “Las Comunidades Autónomas”, en el volumen colectivo La Constitución Española de 1978. Estudio sistemátic.o Ed. Civitas, Madrid.

LUCAS VERDU, P. (1985). El sentimiento constitucional.Aproximación al estudio del sentir constitucional como modo de integración política. Ed.Reus. Barcelona Pág 53 y ss.

MENDEZ ROCASOLANO, M. (2013)."Retos constitucionales sobre derechos humanos: los derechos de los niños desde perspectivas axiológico normativas”, en Revista Thesis Juris - São Paulo, v.2, n.1. Págs 328 a 340.

MENDEZ ROCASOLANO , M.(2014). "Estudio preliminar de la traductora: la teoria de la dinamogenesis de los valores y el derecho a un estado socia en BONAVIDES P. (2014) Del Estado Liberal al Estado Social, Trad María Méndez Rocasolano, Argentina, Ed. Astrea Págs 21 a 35

MOLINA DEL POZO, C. (2015)., Derecho de la Unión Europea. $2^{\text {a }}$ Edición. Ed. Reus. Barcelona. Pág. 305.

MUÑOZ MACHADO, S. (1982). Derecho público de las comunidades autónomas. Ed. Civitas. Madrid Pág. 332-359.

PUNSET BLANCO, R.(1987): El Senado y las Comunidades Autónomas. Ed. Tecnos.Madrid

SOSA WAGNERWARNES,.F.(1979): El control de las Comunidades Autnomas por el Estado e n la Constitución española.

SÁNCHEZ RODRIGUEZ, L.(1981). El articulo 93 y el bloque de la constitucionalidad. Ed. Civitas, Madrid Págs. 242 a 245.

TOLIVAR ALAS, L.(1981). El control del Estado sobre las CC.AA.Ed. Instituto de Estudios de la Administración Local., Madrid, .Pág. 187.

ZARATE CONDE, A.(2014) .Derecho Constitucional Ed, Universidad Ramón Areces. Madrid.. Págs. 394- 395. 


\section{APÉNDICE JURISPRUDENCIAL}

STC 6/1982 BOE 22 DE FEBRERO DE 1982 N²11

STC 49/1988 BOE 22 DE MARZO DE 1988 Nº90

STC 4/1981 BOE 2 DE FEBRERO DE 1981 Nº186

STC 18/1982 BOE 4 DE MAYO DE 1982 Nº 220

STC 35/1982 BOE 14 DE JUNIO DE 1982 N²4

STC 39/1982 BOE 30 DE JUNIO DE 1982 №36 